\title{
When Two Drugs Are Better than Three: Re-Modulating the Therapeutic Plan of a Chronic Obstructive Pulmonary Disease Patient
}

\author{
Antonella lelpo Ernesto Crisafulli \\ Department of Medicine and Surgery, Respiratory Disease and Lung Function Unit, University of Parma, Parma, Italy
}

\section{Keywords}

Chronic obstructive pulmonary disease $\cdot$ Indacaterol/ glycopyrronium - Ventilatory response to exercise - GOLD stage

\begin{abstract}
We present the case of a 77-year-old man diagnosed with chronic obstructive pulmonary disease (COPD) stage $D$ with emphysema phenotype and treated with triple therapy (salmeterol, fluticasone propionate, and tiotropium) for 1 year without relevant improvements in exertional dyspnea and disease impact. After switching to combination therapy with a long-acting $\beta_{2}$-agonist (LABA) and a long-acting muscarinic antagonist (LAMA) (indacaterol/glycopyrronium), we observed, in a 3-month period, a substantial reduction of the modified Medical Research Council (mMRC) dyspnea scale and COPD Assessment Test (CAT) scores. Moreover, the patient reported a reduction of dynamic hyperinflation and an improvement of ventilatory response to exercise.
\end{abstract}

(c) 2018 S. Karger AG, Basel

\section{KARGER}

(C) 2018 S. Karger AG, Basel

E-Mail karger@karger.com

www.karger.com/res

\section{Introduction}

The incremental cardiopulmonary exercise test (CPET) plays an important role in the identification of several dynamic aspects of chronic obstructive pulmonary disease (COPD) [1, 2]. For instance, when evaluating the ventilatory response to exercise, the minute ventilation $\left(\mathrm{V}_{\mathrm{E}}\right)$ is coupled to the rate of carbon dioxide output from the lungs $\left(\mathrm{V}_{\mathrm{CO} 2}\right)$. Moreover, the ratio between $\mathrm{V}_{\mathrm{E}}$ and $\mathrm{V}_{\mathrm{CO} 2}, \mathrm{~V}_{\mathrm{E}} / \mathrm{V}_{\mathrm{CO} 2}$, is known as ventilatory equivalent for $\mathrm{CO}_{2}: \mathrm{V}_{\mathrm{E}}$ increases highly enough to maintain arterial carbon dioxide tension $\left(\mathrm{Pa}_{\mathrm{CO} 2}\right)$ constant [3]. Therefore, the slope of $\mathrm{V}_{\mathrm{E}} / \mathrm{V}_{\mathrm{CO} 2}\left(\mathrm{~V}_{\mathrm{E}} / \mathrm{V}_{\mathrm{CO} 2 \text { slope }}\right)$ and the $\mathrm{Y}$ intercept from $\mathrm{V}_{\mathrm{E}}$ to $\mathrm{V}_{\mathrm{CO} 2}$ regression line $\left(\mathrm{V}_{\mathrm{E}} / \mathrm{V}_{\mathrm{CO} 2 \text { intercept }}\right)$ may provide complementary information on the ventilatory limitation and ventilation control during exercise in COPD patients [4].

The therapeutic approach of COPD is based on bronchodilation, particularly with long-acting $\beta_{2}$-agonist (LABA) and long-acting muscarinic antagonist (LAMA). A report by the Global Initiative for Chronic Obstructive Lung Disease (GOLD) committee has established that the use of inhaled corticosteroids (ICS) should be reserved to

Dr. Ernesto Crisafulli, MD, $\mathrm{PhD}$

Department of Medicine and Surgery, Respiratory Disease and Lung Function Unit University of Parma, Via Rasori 10 IT-43126 Parma (Italy)

E-Mail ernesto.crisafulli@unipr.it 


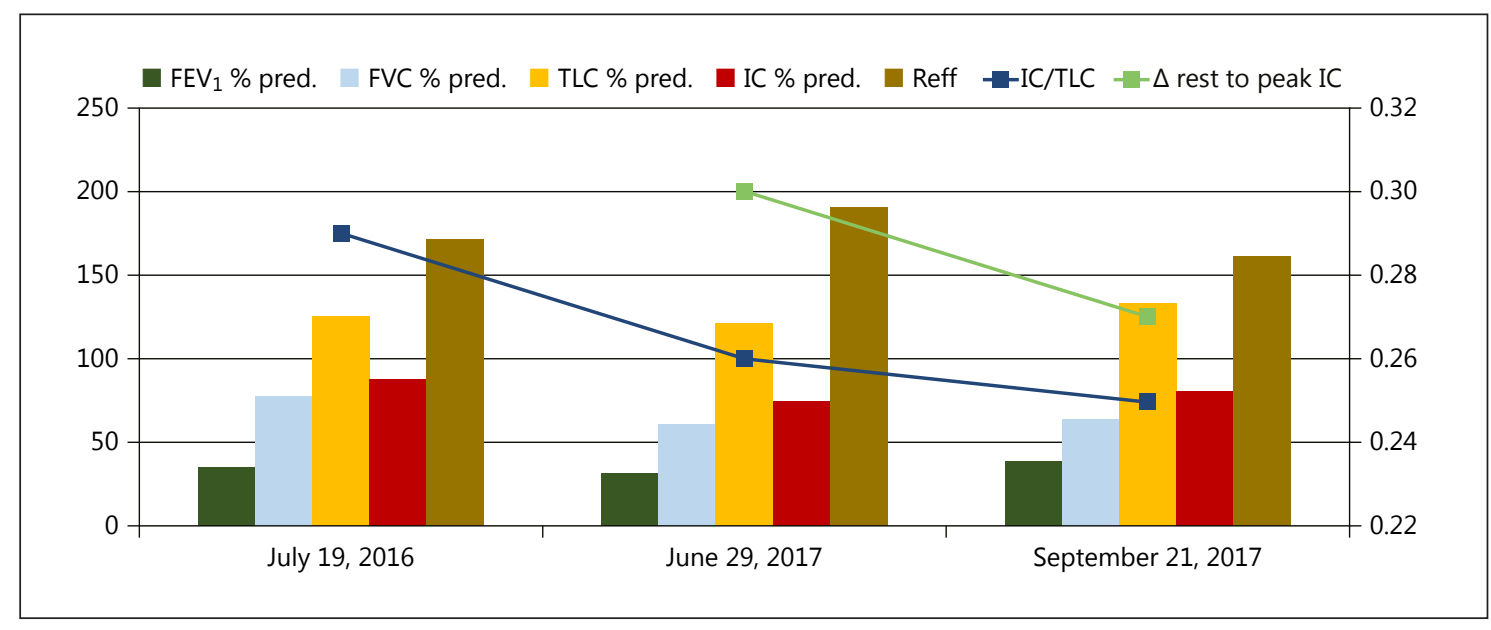

Fig. 1. Lung function and $\Delta$ rest to peak inspiration capacity before and after the use of indacaterol/glycopyrronium. IC, inspiratory capacity; TLC, total lung capacity.

very severe patients (patients in stage D) [5]. In clinical practice, a tailored therapeutic plan is often necessary.

We present the case of a COPD patient needing a remodulation of his therapeutic plan due to persistent exertional dyspnea, with a reduction from 3 drugs (salmeterol, fluticasone propionate, and tiotropium) to 2 (indacaterol/glycopyrronium combination).

\section{Case Description}

In July 2016, a 77-year-old man was diagnosed with severe COPD with emphysema. He had retired from office 10 years earlier, and was used to spend his spare time walking in a nearby wood for hunting until progressive exertional dyspnea prevented him from continuing his promenades. However, he had been neglecting his own symptoms for a long time before seeking medical contact. His past medical history revealed that he was a former smoker who had stopped only in the previous year, with a tobacco exposure of 30 pack-years. Additionally, he suffered from arterial hypertension controlled with enalapril $20 \mathrm{mg}$ plus lercanidipine 10 $\mathrm{mg}$, and he was slightly overweight (body mass index 26). He had no ischemic heart disease, heart failure, or diabetes. His score on the modified Medical Research Council (mMRC) dyspnea scale was 4 , and the impact of disease on his life, as evaluated by the COPD Assessment Test (CAT), was 26. In the previous year, two exacerbations were documented, one of which required hospitalization. His lung function was characterized by a severe airflow obstruction: forced expiratory volume in the first second $\left(\mathrm{FEV}_{1}\right)$ was $0.96 \mathrm{~L}$, corresponding to $35 \%$ of the predicted value. The ratio between $\mathrm{FEV}_{1}$ and forced vital capacity (FVC) was 0.45 ; severe emphysema with static hyperinflation was demonstrated by the low value of the diffusion capacity for carbon monoxide, corresponding to $26 \%$ of the predicted result. The residual volume was extremely high, $5.06 \mathrm{~L}$, corresponding to $189 \%$ of predicted value. According to the pneumologist who visited the patient on admission, the diagnosis was COPD stage $\mathrm{D}$, and the triple therapy with LABA (salmeterol xinafoate $50 \mu \mathrm{g}$ b.i.d.), LAMA (tiotropium bromide $2.5 \mu$ g b.i.d.) and ICS (fluticasone propionate $500 \mu \mathrm{g}$ b.i.d.) was prescribed. Of note, due to the exertional dyspnea the patient could not undergo CPET in order to evaluate his tolerance to exercise and the ventilatory response induced by the exercise itself.

Approximately 1 year later, the patient presented for a followup visit with persisting exertional dyspnea and only minor improvements in mMRC (total score 3) and CAT (score 23). One COPD exacerbation was also documented during that year. On this occasion, the patient was able to perform CPET, which demonstrated a severe reduction of the maximal aerobic capacity (maximal load $60 \mathrm{~W}$, corresponding to $46 \%$ of the predicted value) with a reduced metabolic efficiency (oxygen uptake $\left[\mathrm{V}_{\mathrm{O} 2}\right] 10.8 \mathrm{~mL} /$ $\mathrm{kg} / \mathrm{min}, 45 \%$ of the predicted value, $\left.\mathrm{V}_{\mathrm{O} 2} / \mathrm{W} 7.9 \mathrm{~mL} / \mathrm{min} / \mathrm{W}\right)$. The anaerobic threshold was not reached. A limitation in the ventilator capacity of the patient was documented by a $\mathrm{V}_{\mathrm{E}} / \mathrm{V}_{\mathrm{CO} 2 \text { slope }}$ of 40 (normal values 20-30) and $\mathrm{V}_{\mathrm{E}} / \mathrm{V}_{\mathrm{CO} 2 \text { intercept }}$ of $7.9 \mathrm{~L} / \mathrm{min}$ (normal values $4-5 \mathrm{~L} / \mathrm{min}$ ). According the new GOLD update [5], this patient was restaged as COPD stage $\mathrm{B}$, and, given the persistence of symptoms, his therapeutic plan was modified with the withdrawal of ICS and the introduction of a LABA/LAMA combination (indacaterol $85 \mu \mathrm{g}$ once daily plus glycopyrronium $43 \mu \mathrm{g}$ once daily).

In September 2017, the patient was re-evaluated on a shortterm follow-up. His dyspnea had significantly improved with the indacaterol/glycopyrronium combination therapy, as expressed by a mMRC total score of 1 and a CAT total score of 14 . Following these improvements, the patient was now able to enjoy his activities in open air again. On spirometry, a severe airflow obstruction with static hyperinflation was still evident, but an improvement in lung function parameters was documented (Fig. 1); moreover, improvements in dynamic hyperinflation ( $\Delta$ rest to peak inspiratory capacity from 0.30 to $0.27 \mathrm{~L}$; Fig. 1 ) and exercise-induced ventilatory response, according to $\mathrm{V}_{\mathrm{E}} / \mathrm{V}_{\mathrm{CO} 2}$ slope (now 38) and $\mathrm{V}_{\mathrm{E}} /$ 


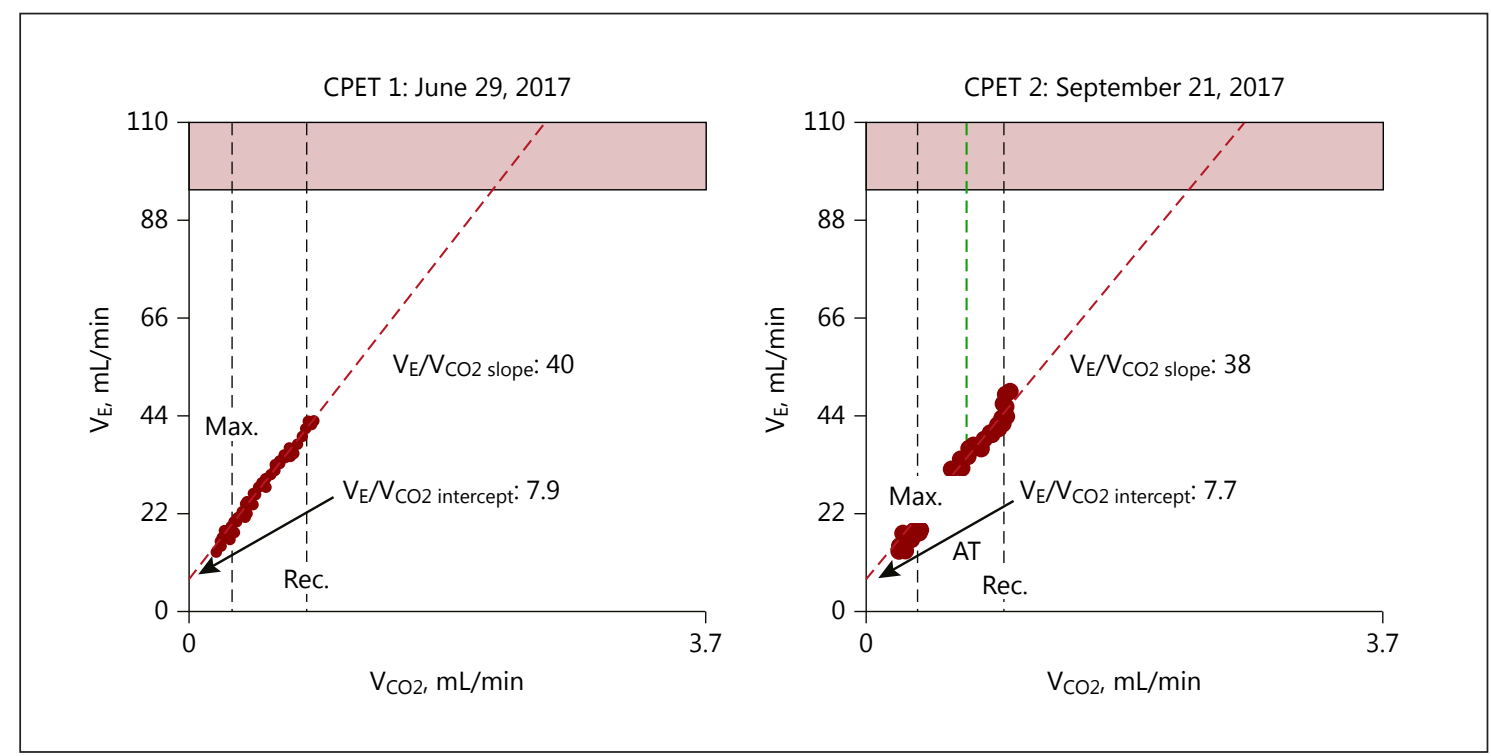

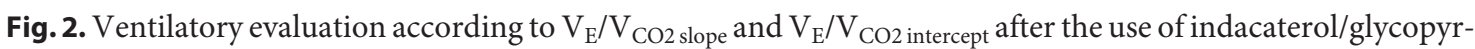
ronium.

$\mathrm{V}_{\mathrm{CO} 2 \text { intercept }}$ (now 7.7 L/min; Fig. 2), were also documented. Additional parameters of CPET showed small improvements in exercise tolerance $\left(62 \mathrm{~W}, 50 \%\right.$ of the predicted value) and $\mathrm{V}_{\mathrm{O} 2}$ of 11.3 $\mathrm{mL} / \mathrm{kg} / \mathrm{min}$ ( $49 \%$ of the predicted value) as well. The anaerobic threshold was reached. Lastly, improvements in the exercise-induced symptom threshold were also documented (from 1.33 to 1.16 for peak dyspnea and from 1.66 to 0.64 for peak fatigue) by Visual Analogue Scale (VAS) with a score of 0-100 corrected by peak workload. Even if the follow-up period at the moment is relatively short, no further exacerbations have been documented so far.

\section{Discussion}

Two recent trials on the role of indacaterol/glycopyrronium $[6,7]$ have already tested the hypothesis that in some patients this combination of drugs (LABA/LAMA) may be more effective than a therapy with ICS for improving symptoms. The case we reported further confirms this finding in a field-practice scenario. In more detail, the FLAME and CRYSTAL studies proved that indacaterol/glycopyrronium is superior to the LABA/ICS (salmeterol/fluticasone) combination [6] in improving lung function and reducing the exacerbation rate, and that this superiority improves lung function and dyspnea after switching from the previous treatments [7]. Moreover, other authors have documented that the indacaterol/glycopyrronium combination in patients with in- creased dyspnea during daily activities is superior to tiotropium and the salmeterol/fluticasone combination [8].

COPD is a complex disease requiring a multifaceted approach [9]. The GOLD committee [5] has recently proposed a multidimensional system to assess each patient's individual risk category, in order to prescribe the most appropriate inhalators. This approach is based on the history (number and frequency) of previous exacerbations, the perceived dyspnea, measured with the mMRC score [10], and the impact of the disease on patients' lives as measured by the CAT score $[11,12]$.

According to the cutoff defined by the GOLD committee [5], our patient presented important symptoms with a high impact (mMRC score $\geq 2$ and CAT score $\geq 10$ ). In this context, the use of the indacaterol/glycopyrronium combination, although evaluated only after 3 months, resulted in improvements, superior to those obtained with the triple therapy during the previous 12 months. Noteworthy, with the triple therapy, the mMRC score improved only from 4 to 3 and the CAT score decreased only from 26 to 23, as compared with more profound reductions obtained with the indacaterol/glycopyrronium combination (mMRC score -2 points and CAT score -9 points). Moreover, the patient experienced a remarkable benefit in his daily life activities after switching treatment, being able once again to enjoy open-air activities, as already reported elsewhere [8]. 
In COPD patients, $\mathrm{V}_{\mathrm{E}} / \mathrm{V}_{\mathrm{CO} 2}$ slope and $\mathrm{V}_{\mathrm{E}} / \mathrm{V}_{\mathrm{CO} 2}$ intercept provide complementary information on the ventilatory limitation to exercise $[2,4]$; any alteration in these parameters may correspond to changes in end-expiratory lung volume and tidal volume.

In mild-to-moderate COPD patients, emphysema (evaluated at thoracic high-resolution CT scan by the percentage of low attenuation areas) has a close relationship with the different characteristics of ventilatory response to exercise, in particular $\Delta$ rest to peak and $\mathrm{V}_{\mathrm{E}} / \mathrm{V}_{\mathrm{CO} 2 \text { slope }}$ [2]. As compared with controls, in mild and moderate COPD patients there is an increase of $\mathrm{V}_{\mathrm{E}} / \mathrm{V}_{\mathrm{CO} 2}$ slope [13]. The $V_{E} / V_{C O 2}$ intercept, which is highly correlated with the amount of dead space [14], increases progressively in COPD patients, reflecting the progression of airflow obstruction [13]. In our patient, the change of $\mathrm{V}_{\mathrm{E}} / \mathrm{V}_{\mathrm{CO} 2 \text { slope }}$ and $\mathrm{V}_{\mathrm{E}} / \mathrm{V}_{\mathrm{CO} 2}$ intercept may represent the beneficial effect of the indacaterol/glycopyrronium combination on ventilatory limitation.

Changes in operational lung volumes, assessed every 2 min during exercise and at peak exercise, express dynamic hyperinflation $(\mathrm{DH})$ in cases of improvements greater than $0.14 \mathrm{~L}[1,15]$; our patient, who had a severe degree of $\mathrm{DH}$, showed a reduction of $\Delta$ rest to peak from 0.30 to $0.27 \mathrm{~L}$ after treatment with the indacaterol/glycopyrronium combination, thus indicating a reduction of $\mathrm{DH}$. These dynamic changes during exercise could be the reason for the improvement of exertional dyspnea. Indeed, improvements of dyspnea and leg fatigue were proved at the maximal effort of CPET [16].

\section{Conclusion}

In this case report, a severe emphysematous COPD patient obtained significant benefit from the re-modulation of his therapy from 3 to 2 drugs (indacaterol/glycopyrronium), with an improvement in the degree of exertional dyspnea. This may be related not only to an improvement in lung function, as expressed by $\mathrm{FEV}_{1}$, but also thanks to an improvement of $\mathrm{DH}$, ventilatory response to exercise, and dead space, expressed by $\Delta$ rest to peak, $\mathrm{V}_{\mathrm{E}} / \mathrm{V}_{\mathrm{CO} 2 \text { slope, }}$ and $\mathrm{V}_{\mathrm{E}} / \mathrm{V}_{\mathrm{CO} 2}$ intercept, respectively.

Further studies are needed in COPD patients to clarify the role of the association of indacaterol/glycopyrronium on ventilatory limitation as a new pharmacological target.

\section{Acknowledgement}

The authors thank Luca Giacomelli, PhD, for providing medical writing on behalf of Content Ed Net; this assistance was funded by Novartis Farma SpA.

\section{Financial Disclosure and Conflicts of Interest}

Antonella Ielpo declares no conflict of interest related to this paper. Ernesto Crisafulli has received compensation for lectures by AstraZeneca, Boehringer-Ingelheim, and Chiesi Farmaceutici.

\section{References}

1 Puente-Maestu L, Palange P, Casaburi R, Laveneziana P, Maltais F, Neder JA, O’Donnell DE, Onorati P, Porszasz J, Rabinovich R, Rossiter HB, Singh S, Troosters T, Ward S: Use of exercise testing in the evaluation of interventional efficacy: an official ERS statement. Eur Respir J 2016;47:429-460.

2 Crisafulli E, Alfieri V, Silva M, Aiello M, Tzani P, Milanese G, Bertorelli G, Sverzellati N, Chetta A: Relationships between emphysema and airways metrics at high-resolution computed tomography (HRCT) and ventilatory response to exercise in mild to moderate COPD patients. Respir Med 2016;117:207214.

3 Wasserman K, Hansen JE, Sue DY, et al (eds): Principles of Exercise Testing and Interpretation. Lippincott Williams and Wilkins, Philadelphia, 1994, pp 143-162.
4 Teopompi E, Tzani P, Aiello M, Gioia MR, Marangio E, Chetta A: Excess ventilation and ventilatory constraints during exercise in patients with chronic obstructive pulmonary disease. Respir Physiol Neurobiol 2014;197: 9-14

5 Vogelmeier CF, Criner GJ, Martinez FJ, Anzueto A, Barnes PJ, Bourbeau J, Celli BR, Chen R, Decramer M, Fabbri LM, Frith P, Halpin DM, López Varela MV, Nishimura M, Roche N, Rodriguez-Roisin R, Sin DD, Singh D, Stockley R, Vestbo J, Wedzicha JA, Agustí A: Global Strategy for the Diagnosis, Management, and Prevention of Chronic Obstructive Lung Disease 2017 report. GOLD executive summary. Am J Respir Crit Care Med 2017; 195:557-582.
6 Wedzicha JA, Banerji D, Chapman KR, Vestbo J, Roche N, Ayers RT, Thach C, Fogel R, Patalano F, Vogelmeier CF; FLAME Investigators. Indacaterol-glycopyrronium versus salmeterol-fluticasone for COPD. N Engl J Med 2016;374:2222-2234.

7 Vogelmeier CF, Gaga M, Aalamian-Mattheis M, Greulich T, Marin JM, Castellani W, Ninane V, Lane S, Nunez X, Patalano F, Clemens A, Kostikas K; CRYSTAL study investigators: Efficacy and safety of direct switch to indacaterol/glycopyrronium in patients with moderate COPD: the CRYSTAL open-label randomised trial. Respir Res 2017;18:140.

8 Mahler DA, Keininger DL, Mezzi K, Fogel R, Banerji D: Efficacy of indacaterol/glycopyrronium in patients with COPD who have increased dyspnea with daily activities. Chronic Obstr Pulm Dis 2016;3:758-768. 
9 Woodruff PG, Agusti A, Roche N, Singh D, Martinez FJ: Current concepts in targeting chronic obstructive pulmonary disease pharmacotherapy: making progress towards personalised management. Lancet 2015;385: 1789-1798.

10 Fletcher CM, Elmes PC, Wood CH: The significance of respiratory symptoms and the diagnosis of chronic bronchitis in a working population. Br Med J 1959;2:257-266.

11 CAT Development Steering Group: COPD Assessment Test - Healthcare Professional User Guide, 2014. Available from: http:// www.catestonline.org.
12 Jones PW, Brusselle G, Dal Negro RW, Ferrer M, Kardos P, Levy ML, Perez T, Soler Cataluña JJ, van der Molen T, Adamek L, Banik N: Properties of the COPD assessment test in a cross-sectional European study. Eur Respir J 2011;38:29-35.

13 Neder JA, Arbex FF, Alencar MC, O’Donnell CD, Cory J, Webb KA, O’Donnell DE: Exercise ventilatory inefficiency in mild to endstage COPD. Eur Respir J 2015;45:377-387.
14 Gargiulo P, Apostolo A, Perrone-Filardi P, Sciomer S, Palange P, Agostoni P: A non invasive estimate of dead space ventilation from exercise measurements. PLoS One 2014;9: e87395.

15 Laveneziana P, Webb KA, Ora J, Wadell K, O'Donnell DE: Evolution of dyspnea during exercise in chronic obstructive pulmonary disease: impact of critical volume constraints. Am J Respir Crit Care Med 2011;184:13671373.

16 Tzani P, Aiello M, Colella M, Verduri A, Marangio $\mathrm{E}$, Olivieri $\mathrm{D}$, Chetta $\mathrm{A}$ : Lung diffusion capacity can predict maximal exercise in apparently healthy heavy smokers. J Sports Sci Med 2008;7:229-234. 